\title{
Parental suspicion and identification of hearing impairment
}

\author{
P $M$ Watkin, $M$ Baldwin, S Laoide
}

\begin{abstract}
The contribution of parental suspicion in the original identification of a 16 year cohort of 171 children with varying degrees of hearing impairment who were screened and identified in childhood was studied. Only a quarter of the children with permanent hearing loss were identified as a result of parental concern. The presence of parental suspicion preceding the audiological diagnosis was also measured. Of the children with severe or profound deafness, the parents only suspected the presence of hearing loss in $44 \%$. Parental suspicion was even lower for those with a mild or moderate permanent hearing loss, and for those with an otherwise symptomless conductive hearing loss caused by otitis media with effusion. Some parents did identify hearing impairment in their children, and parental suspicion should never be professionally disregarded. Most parents, however, experienced initial difficulty in recognising their children's hearing loss, even when the children were comparatively old. The study confirms the need to continue to identify deafness early by both parental vigilance and sensitive hearing screening programmes.
\end{abstract}

Since the pioneering studies of the Ewings in Manchester, ${ }^{1}$ screening the hearing of infants and young children has become an established component of surveillance programmes in. the United Kingdom. Child health surveillance is currently being critically reviewed, ${ }^{2}$ however, and there is some scepticism about the validity of identifying childhood deafness by screening programmes. ${ }^{3}$ The validity of screening programmes and test methods has been questioned, and a programme of screening for hearing impairment has been recommended in the report of the Joint Working Party on Child Health Surveillance. ${ }^{4}$ Such recommendations accept that there is a need to screen for hearing loss but this need is not universally acknowledged.

The rationale behind screening for hearing loss is the supposition that there are many children with impaired hearing that has not been diagnosed and that early detection will improve their eventual outcome. The scientific evidence for this is sparse, although most people would accept that there is sufficient evidence to justify the early identification of infants with profound, severe (and probably also moderate) permanent bilateral deafness. ${ }^{5}$ The need to identify such children by screening, however, depends on the belief that parents cannot tell that their children are deaf; this assumption is increasingly being questioned.

The National Children's Bureau has put forward the view that parents are the most sensitive observers of their own children. ${ }^{6}$ This view has also been expressed in other reports, ${ }^{7}$ and was partly supported by the findings of the United Kingdom contribution to the European Community survey of childhood deafness. ${ }^{8}$

Although the widespread implementation of hearing screening programmes implies that many do not accept that parents can identify hearing impairments in their children, there are few studies that support this view. Simmons noted that an important cause of delayed audiological rehabilitation was parents who did not accept the diagnosis, ${ }^{9}$ but much current opinion urges the use of parental suspicions in the identification of hearing impairments.

In some districts the introduction of neonatal screening for those at risk of hearing loss has resulted in a reduced yield from later behavioural screening programmes, making them less cost effective. Although a restricted neonatal screening programme has been in operation in Waltham Forest Health Authority for several years, a study of the causes of deafness in the district over the past 16 years suggested that only $40 \%$ of children with either moderate, severe, or profound hearing loss will be identified by such methods. The present study was therefore undertaken to measure the contribution that parental suspicion has made in the identification of childhood deafness. This contribution has assumed great importance, not only because of the reduced cost effectiveness of the behavioural screening programmes that remain to identify those infants not identified by the restricted neonatal screening, but also because of the repeated emphasis on the role of parents in knowing when their children are deaf. Identification by later behavioural screening may therefore be unnecessary.

\section{Subjects and methods}

Waltham Forest Health Authority serves a population of around 250000 in east London that varies from high urban deprivation to relative affluence. Of the total population, $17 \cdot 5 \%$ (and nearly one third of the children) are Asian, and the district has the largest Pakistani community of any London borough. Since the 1960 s the health authority has provided a community based audiology service employing medical audiologists, technicians, and scientists. The service receives both screening and non-screening referrals of children requiring 
audiological assessment and also collects epidemiological data on deafness within the district.

Data on all children known to have permanent hearing loss who were resident in the district in 1989 and born after January 1973 were studied. A total of 195 children were identified, but 24 with inadequate records or with obvious atresia of the external auditory canal were excluded. Data on 111 children with bilateral permanent hearing loss and 60 with unilateral permanent hearing loss were therefore included in the study. The hearing losses were classified according to the recommendations of the British Society of Audiology. ${ }^{10}$ The prevalence of different types and degrees of hearing loss within the district is known. The 171 children studied under represented all types and degrees of hearing loss without undue bias. Incomplete ascertainment was inevitable in a study of children born during a 16 year period, and inclusion of all infants and young children with all types and degrees of hearing loss would be impossible. The group was otherwise representative of a typical population of children with permanent hearing loss within a district of similar social and demographic characteristics (table 1).

The data were studied in various ways. First the comparative yields from screening programmes and from other referrals were calculated from the original records that detailed the initial referral. Although yield is usually calculated as the percentage of children with hearing impairment correctly identified from those screened, in order that direct comparisons could be made from the screening and non-screening referrals, yield was calculated as a percentage of the cohort defined by age. Only those children initially identified by specific screening programmes were considered as the yield from screening.

During the period of the study (children born from January 1973 until December 1988) infant distraction tests, at the age of 8 months, and infant and junior school sweep tests were undertaken. A hearing screening programme for 3 year olds was introduced in 1984, and children identified by this screen were included. Since 1987 a restricted neonatal screening programme has also been undertaken, but these children were excluded from the study because of the bias in favour of yield from screening. Children identified other than by screening were referred by general practitioners, from acute paediatric and ear, nose, and throat departments, from the child development centre, after annual hearing

Table 1 Known prevalence of permanent hearing loss within the district and prevalence of children with such loss included in the study

\begin{tabular}{|c|c|c|c|}
\hline Average $d B$ hearing loss* & $\begin{array}{l}\text { Prevalencel } \\
1000 \\
\text { in district }\end{array}$ & $\begin{array}{l}\text { No of } \\
\text { children } \\
\text { in study } \\
\text { ( } n=171)\end{array}$ & $\begin{array}{l}\text { Prevalencel } \\
1000 \\
\text { within } \\
\text { study group }\end{array}$ \\
\hline $\begin{array}{l}\text { Mild bilateral }(21-40 \mathrm{~dB}) \\
\text { Moderate bilateral }(41-70 \mathrm{~dB}) \\
\text { Severe bilateral }(71-95 \mathrm{~dB}) \\
\text { Profound bilateral }(>95 \mathrm{~dB}) \\
\text { Unilateral }(>55 \mathrm{~dB})\end{array}$ & $\begin{array}{l}1 \cdot 3 \\
0.8 \\
0 \cdot 4 \\
0.7 \\
2 \cdot 4\end{array}$ & $\begin{array}{l}39 \\
33 \\
17 \\
22 \\
60\end{array}$ & $\begin{array}{l}0.8 \\
0.6 \\
0.3 \\
0.4 \\
1.2\end{array}$ \\
\hline
\end{tabular}

*Averaged in better ear in bilateral loss and deaf ear in unilateral loss. tests in special schools, by speech therapists, educationalists, and community child health services, and directly by parents. Any referral not resulting from a specified hearing screening programme constituted a 'vigilant' referral. If it did not result from routine hearing surveillance-for example, in a special school or within the child development centre-we considered that it may have been the result of parental concern, and those children were counted separately.

Identification following failure at a screening test, however, did not necessarily imply that the parents were not already aware that the child had a hearing impairment. Parental suspicion preceding the diagnosis of permanent hearing loss was therefore also recorded. This was possible because all the parents of children referred to the audiology service were sent a questionnaire for completion after the referral but before the diagnostic assessment. The questionnaire asked: 'Do you think your child has any problem with his/her hearing?' Because the question was asked after referral we acknowledged that the answers would be biased in favour of parental suspicion. This bias would, however, be less than it would have been if we had relied on retrospective parental recall. The sensitivity of parental suspicion was calculated as the percentage of parents who correctly identified that their children had impaired hearing before the diagnostic assessment of all those with children with hearing loss. The sensitivity of parental suspicion was also measured for the shape of the hearing loss (defined according to the criteria recommended by Fisch). ${ }^{11}$

The sensitivity of parental suspicion was also calculated for 250 children with otitis media with effusion whose deafness was identified from the screening programmes. Only those children with persistent otitis media who required surgical ventilation of the middle ear were included. The children were taken from the most recent referrals before the onset of the study, and included 75 who had initially failed the 8 month screen, 50 who had failed the intermediate hearing screen at 3 years of age, 75 who had failed the infant sweep test at school, and 50 who had failed the junior sweep test. Fewer children were picked up from the intermediate and junior sweep tests because fewer children were identified from these screens who had persistent otitis requiring surgical treatment.

The sensitivity of the screening tests was also measured retrospectively. These computations were undertaken for children with severe or profound hearing loss born before 1986, and for children with mild or moderate hearing loss born before 1983. Identification of children younger than this with hearing impairments may not have been complete and the measurements of sensitivity of the screening tests would therefore be biased.

\section{Results}

THE COMPARATIVE YIELDS FROM SCREENING AND OBSERVATION

The results of the comparative yields are summarised in table 2 . For those 39 children with 
Table 2 Method of initial identification of children with permanent hearing loss born between fanuary 1973 and December 1988 (171 of 51250$)$

\begin{tabular}{|c|c|c|c|c|c|c|}
\hline \multirow{3}{*}{$\begin{array}{l}\text { Degree of } \\
\text { hearing loss }\end{array}$} & \multicolumn{6}{|c|}{ Method of identification of hearing loss } \\
\hline & \multicolumn{2}{|l|}{ Screening } & \multicolumn{2}{|c|}{$\begin{array}{l}\text { Noticed by person } \\
\text { other than parent }\end{array}$} & \multicolumn{2}{|c|}{ Noticed by parent } \\
\hline & No $(\%)$ & Yield & No (\%) & Yield & No (\%) & Yield \\
\hline $\begin{array}{l}\text { Mild or moderate } \\
\text { bilateral }(n=72) \\
\text { Severe or profound }\end{array}$ & $51(71)$ & 0.099 & $7(10)$ & 0.014 & $14(19)$ & 0.027 \\
\hline $\begin{array}{r}\text { bilateral }(n=39) \\
\text { Unilateral }(n=60)\end{array}$ & $\begin{array}{l}18(46) \\
34(57)\end{array}$ & $\begin{array}{l}0.035 \\
0.066\end{array}$ & $\begin{array}{r}11(28) \\
8(13)\end{array}$ & $\begin{array}{l}0.021 \\
0.016\end{array}$ & $\begin{array}{l}10(26) \\
18(30)\end{array}$ & $\begin{array}{l}0.019 \\
0.035\end{array}$ \\
\hline Total & $103(60)$ & $0 \cdot 200$ & $26(15)$ & 0.051 & $42(25)$ & 0.082 \\
\hline
\end{tabular}

severe or profound bilateral hearing loss just under a half $(18,46 \%)$ were identified by a hearing screening test. The hearing screening programme that identified all but one of them was the infant distraction test performed at 8 months. The remaining child was identified at the infant school sweep test, but his hearing loss had shown definite audiometric progression. Over this period only one child had a definite false negative result from the infant hearing screening programmes, and she was eventually diagnosed at 2-3 years of age after being referred because she was thought to be deaf. The retrospective sensitivity of the infant distraction test was $93 \%$. Identification by observation, however, accounted for just over half $(21,54 \%)$ of the children with such a loss. Eleven were referred for audiological assessment from the child development centre or the acute paediatric or community child health services. Three of them had failed the infant distraction test, although eventual diagnosis was delayed because the child was already under paediatric surveillance. Ten of the referrals were possibly the result of parental concern. Only the child previously mentioned, however, had a false negative result from the infant distraction test. The remainder either were identified before the screening programme, had moved into the district, or had definitely progressive or acquired hearing loss.

Of those 72 children with mild or moderate bilateral hearing loss, most $(51,71 \%)$ were identified through the screening programmes, 29 out of the 51 being identified by the school sweep tests. Four were identified from the intermediate hearing screening programme, introduced in 1984, and 18 from the infant screening programme. Twenty one (29\%) were identified because of suspicion, seven after hearing surveillance in the special schools or the child development centre, or after referral from other child health or paediatric departments. None of these identifications were considered to have been the result of parental concern about their children's hearing. Fourteen others (19\% of all those with mild or moderate loss) were referred because of possible parental suspicion, mainly by general practitioners or the community child health services. Although a quarter of the children with mild or moderate hearing loss were identified by the infant screening programme, the overall retrospective sensitivity of the programme in identifying those children with moderate bilateral hearing loss was $36 \%$, and in identifying those with mild loss it was $17 \%$.
Of the 60 children with unilateral hearing loss, $34(57 \%)$ were identified by screening. Twenty nine of the 34 were identified by school sweep tests, three by the intermediate screening, and two by the infant distraction test; 26 with such hearing loss were referred because of suspicion. Eight of these referrals came from professionals, and the other 18 could have been initiated by parental concern. These 18 represented $30 \%$ of all those with unilateral hearing loss.

PRESENCE OF PARENTAL SUSPICION PRECEDING THE DIAGNOSIS

The degree of parental suspicion preceding the diagnosis of the hearing impairment is shown in the figure. Of the 39 children with bilateral severe or profound hearing loss, less than half of the parents $(49 \%)$ suspected that their children had any loss of hearing. The sensitivity of parental suspicion varied with the age of identification. For those children identified in infancy, only $44 \%$ of their parents suspected the presence of hearing loss, and between the ages of 1 and 3 years this rose to $56 \%$. Five of the children with such a loss had progressive or acquired hearing loss or had moved into the district, and were not identified until after the age of 3 years. Even in these five older children, only two of the parents believed that their chil-

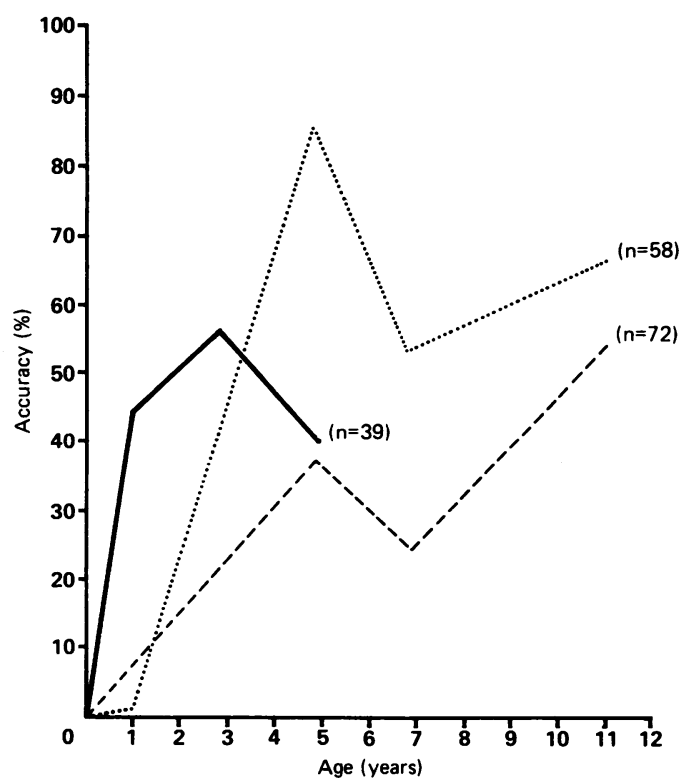

Sensitivity of parental suspicion preceding diagnosis of permanent hearing loss in childhood. Mild or moderate hearing loss (- - ), severe or profound hearing loss (-), and unilateral hearing loss $(\cdot \cdot)$. 
dren had hearing loss after referral for diagnostic assessment.

Of the 72 children with mild or moderate permanent bilateral loss, the sensitivity of parental suspicion was even lower.

If all 72 are considered together, in 21 (29\%) the parents were suspicious. In infancy only one of 15 parents considered that their child had impaired hearing. Between the ages of 1 and 3 years the sensitivity of parental suspicion rose to $29 \%$, and between 3 and 5 years to $37 \cdot 5 \%$. At the infant school entry sweep test, however, the sensitivity fell away to $24 \%$, before rising again to $54 \%$ for children over the age of 7 years. Of eight children first identified between the ages of 7 and 9 years, five parents were not concerned about their hearing.

Parental suspicion was greatest in those children with unilateral hearing loss. Although sensitivity was zero in infancy and only $40 \%$ between the ages of 1 and 3 years, after this age but before school entry it rose to $85 \%$. Between the ages of 5 and 7 years it fell to $52 \%$, but at junior school age and above it rose again to $70 \%$.

The sensitivity of parental suspicion was also examined by the shape of the audiometric loss (table 3). For all degrees of hearing impairment the parental suspicion was least sensitive when the hearing loss was a sloping high frequency impairment, and most sensitive when the hearing loss was 'flat'.

The sensitivity of parental suspicion was also measured for 250 children with otitis media with effusion. Because the methods used were different (only those who had failed screening and who had persistent otitis media with effusion requiring surgical middle ear ventilation were considered in this part of the study), the results have been shown separately (table 4). They confirmed a low level of parental suspicion in children under school age.

\section{Discussion}

In a district with high urban deprivation and a

Table 3 Sensitivity of parental suspicion by degree and shape of hearing loss $(n=111)$

\begin{tabular}{lll}
\hline $\begin{array}{l}\text { Type, degree, and shape } \\
\text { of hearing loss }\end{array}$ & No of children & $\begin{array}{l}\text { No (\%) of } \\
\text { parents } \\
\text { suspicious of } \\
\text { hearing loss }\end{array}$ \\
\hline $\begin{array}{l}\text { Mild or moderate: } \\
\text { Flat }\end{array}$ & 18 & $9(50)$ \\
$\begin{array}{l}\text { Gradually sloping high } \\
\text { frequency }\end{array}$ & 20 & $7(35)$ \\
$\begin{array}{l}\text { Sharply sloping high } \\
\text { frequency }\end{array}$ & 20 & $2(10)$ \\
'V' 'U' shaped & 9 & $3(33)$ \\
Hill shaped & 5 & 0 \\
$\begin{array}{l}\text { Severe or profound: } \\
\text { Flat }\end{array}$ & 25 & $14(56)$ \\
$\begin{array}{l}\text { Sloping high frequency } \\
\text { 'V' or 'U' shaped }\end{array}$ & 9 & $4(44)$ \\
\hline
\end{tabular}

Table 4 Sensitivity of parental suspicion preceding diagnosis of a temporary hearing loss in childhood

\begin{tabular}{lll}
\hline Screening test & $\begin{array}{l}\text { No of } \\
\text { children }\end{array}$ & $\begin{array}{l}\text { No (\%) of } \\
\text { parents suspicious } \\
\text { of hearing loss }\end{array}$ \\
\hline Infant distraction test & 75 & $10(13)$ \\
Intermediate test & 50 & $14(28)$ \\
Infant school sweep & 75 & $43(57)$ \\
Junior school sweep & 50 & $19(33)$ \\
\hline
\end{tabular}

mixed ethnic population, the identification of childhood deafness is dependent on screening, and professional and parental suspicion. Despite a locally based diagnostic hearing assessment centre with a long standing policy of open access, the contribution of parental suspicion in the identification of permanent hearing loss in their children has been small, and most of such children have been identified by hearing screening programmes. Despite the fact that the study was biased towards the presence of parental suspicion that their child's hearing was impaired, the results suggest that most parents find the identification of such deafness a difficult task.

The complementary contribution of screening and suspicion is illustrated in the study of those children with severe or profound deafness. Although the infant screening programme was over $90 \%$ sensitive, suspicion accounted for half of the initial identifications, and referral instigated by parental concern for about a quarter. It is considered by most people that such children should be identified early in infancy, and to this end many districts are now undertaking neonatal screening for those considered to be 'at risk'. In a district of similar social and demographic characteristics, between four and five severely deaf children will be identified each year. A study of our childhood population with this degree of hearing loss has specified that only around $40 \%$ will be identified by such an 'at risk' programme. Two or three children each year will therefore remain to be identified by later behavioural screens or suspicion. The results of the present study suggest that only one of these children will be identified by parental suspicion in infancy and although the probability of the parent suspecting the presence of such a hearing loss increases between the ages of 1 and 3 years, the sensitivity of parental suspicion, even in the older preschool child, is less than $50 \%$. The necessary identification of such children is therefore dependent on continuing the infant distraction screening programme, unless identification as a result of parental suspicion can be appreciably increased.

As predicted, parents found it even more difficult to identify hearing impairments in their children if the loss was only mild or moderate. This low level of parental suspicion was present both in otherwise symptomless children with otitis media with effusions and in those with permanent hearing loss. It is not clear whether otherwise asymptomatic children with 'glue ear' need to be identified by screening in early childhood. Many consider it important, however, to identify those children with permanent mild hearing loss in early childhood, and those with a moderate permanent hearing impairment in infancy. ${ }^{5}$ Within the district studied, out of the 16 year cohort examined with such a loss, less than $40 \%$ would have been identified from an 'at risk' register.

The prevalence indicates that seven or eight children with such losses should be identified each year. Four or five of them require identification by suspicion or behavioural screens. Despite the sensitivity of the infant distraction test in identifying severe or profound losses, 
and the $86 \%$ coverage of the programme with regular field work teaching over many years, its sensitivity in identifying lesser degrees of permanent hearing loss was less than $50 \%$. Equally disappointing, however, is the low level of parental suspicion. Less than $10 \%$ of parents suspected that their child had such a hearing loss in infancy, and the sensitivity of parental suspicion only rose to over $50 \%$ for children more than 7 years old. If it is valid to identify children with moderate losses in infancy, the sensitivity of the infant screening programme must be improved, but the index of parental suspicion must also be increased. In view of the lack of sensitivity of both, the place of a sensitive intermediate preschool screen is clear.

Surprisingly, parents were much more likely to identify children with unilateral hearing loss before they attained school age. It is possible that the higher index of parental suspicion (85\% for children between 3 and 5 years old) resulted from the bias of the study (that is, parents found it easier to acknowledge the presence of unilateral hearing loss after screening failure but before the diagnostic audiological assessment). The results also confirmed, however, that the yield from direct parental suspicion was highest for this type and degree of hearing loss. Although traditionally it has been considered that such losses do not result in disability, many now consider that unilateral deafness requires identification after infancy but before school entry. ${ }^{12}$ The contribution of parental suspicion could appreciably assist in this identification.

Most of the unilateral hearing losses, and the mild and moderate bilateral hearing losses, were identified by the school sweep test. When they are identified at such an age the sensitivity of parental suspicion falls. Although the reasons for this remain speculative, it is probable that if the children had not been identified by either parental suspicion or screening in the preschool years, the parents found it difficult to acknowledge the presence of hearing loss at this relatively late age. Interestingly, the index of suspicion rose again in the older children at primary school. A subsequent survey of these children has confirmed that in most cases it was the child who heightened the sensitivity of parental suspicion at this age, and this suspicion could therefore be usefully 'tapped' after the infant school sweep test by interviewing the child.

Identification after parental suspicion has been improved in some areas by the introduction of a systematic way of assessing it, and the studies undertaken in Nottinghamshire ${ }^{1314}$ have shown the validity of such an approach. McCormick introduced a checklist of 'hints' by which parents could gauge whether their infant's reaction to sound was satisfactory. ${ }^{15}$ Such a method is valuable because it is a cost effective way of identifying hearing impairment compared with other methods, which require professional hearing screening tests. Probably its greatest virtue is that some parents are able to identify hearing impairment correctly in their children, and a systematic approach that takes account of such parental concerns ensures that these suspicions are professionally recognised and referral for diagnostic audiological assessment is immediately available.

The present study was undertaken in a district where the degree of urban deprivation and the wide ethnic background of the population have previously precluded the systematic use of a parental questionnaire as a means of identifying deafness. Although such a method has now been introduced and is being evaluated, the present study confirms that most parents do not at first accept that their children have hearing impairments, even after they have failed hearing screening tests. Most children with permanent hearing loss were identified by screening. To replace, rather than complement, screening programmes by methods that rely on parental opinion alone will result in many children with hearing impairments remaining unidentified until their handicaps are obvious.

The results of the study confirm the complex association between suspicion and screening in the identification of all types and degrees of hearing losses. It is not possible to replace one method by the other without affecting this identification. Methods to improve both screening programmes and heighten parental suspicion are therefore required.

1 Ewing IR, Ewing AWG. The ascertainment of deafness in infancy and early childhood. F Laryngol Otol 1944;59: $309-38$.

2 Butler J. Child health surveillance in primary care. London: HMSO, 1989.

3 Stewart-Brown S, Haslum MN. Screening for hearing loss in childhood; a study of national practice. $\mathrm{Br} M$ M $\mathcal{F} 1987 ; 294$ 1386-8.

4 Hall DMB, ed. Health for all children. Oxford: Oxford University Press, 1989.

5 Sancho J, Hughes E, Davis A, Haggard M. Epidemiological basis for screening hearing. In: McCormick B, ed. Paediabasis for screening hearing. In: McCormick B, ed. Paedia-
tric audiology. London: Taylor and Francis, 1988:1-36. tric audiology. London: Taylor and Francis, 1988:1-36.
6 National Children's Bureau. Investing in the future. London: National Children's Bureau, 1987.

7 MacFarlane A. Child health services in the community: making them work. Br Med f 1986;293:222-3.

8 Martin JAM, Bentzen O, Colley JRT, et al. Childhood deaf ness in the European community. Scand Audiol 1981; 10:165-74.

9 Simmons FB. Diagnosis and rehabilitation of deaf newborns ASHA 1980;22:475.

10 British Society of Audiology Recommendation. Descriptors for pure tone audiograms, $B r \mathcal{F}$ Audiol 1988;22:123.

11 Fisch $\mathrm{L}$. The aetiology of congenital deafness and audiometric patterns. F Laryngol Otol 1955;69:479-93.

12 Bess FH, Klee T, Culbertson JL. Identification, assessmen and management of children with unilateral sensori-neural hearing loss. Ear Hear 1986;7:43-5.

13 Latham AD, Haggard MP. A pilot study to detect hearing impairment in the young. Midwife, Health Visitor, and Community Nurse 1980:16:370-4.

14 Hitchings V, Haggard MP. Incorporation of parental suspicion in screening infants hearing. $B r \mathcal{f}$ Audiol 1983;17: $71-5$.

15 McCormick B. Screening for hearing impairment in the young child. London: Croom Helm, 1988. 